\section{Mapeamento, Processo, Conexões: a cartografia como metodologia de pesquisa}

Mapping, Process, Connections: cartography as methodology for research

Resumo: $O$ seguinte artigo discorre a respeito da cartografia como metodologia de pesquisa, conforme apresentada por Deleuze e Guattari. O objetivo é explora suas possibilidades de investigação e formas de construir a pesquisa, pois o mesmo não apresenta etapas ou fases rigidamente estabelecidas para seguir. Assim, através do que é apresentado por autores que estudam a metodologia, como Kastrup, alguns pontos são explorados e comentados.

Palavras-chave: Metodologia da pesquisa em artes; Cartografia; Rizoma.

Abstract: The following article is about cartography as a research methodology as presented by Deleuze and Guattari. The objective is to explore its investigation possibilities and means to build research as there are no steps or phases established to be followed rigidly. Thus, through studying what has been presented by authors who study this methodology, such as Kastrup, some points are explored and commented.

Keywords: Research in art methodology; Cartography; Rhizome

\section{DARALEL@3I}

A pesquisa em poéticas visuais caracteriza-se por integrar teoria e prática, ou seja, o pesquisador deve produzir sua obra juntamente com o aporte teórico que a sustenta. Mas não é necessariamente a obra finalizada o objetivo da pesquisa, e sim o percurso, o processo de instauração e a investigação que acontece durante esse caminho, gerando diferentes conexões, significados, questionamentos.

Tudo isso agrega no desenvolvimento da pesquisa, mas para que o pesquisador não fique perdido em um labirinto de aleatoriedade, onde tudo pode se conectar e somar, a abordagem metodológica auxilia nessa produção, ajudando a organizar o pensamento e provocar estágios que podem enriquecer a pesquisa. Não é como um guia rígido a ser seguido friamente, mas algo para ajudar o pesquisador de acordo com as necessidades de seu trabalho, pois como diz Icleia Cattani (2002, p. 49), "a pesquisa em arte e pesquisa sobre arte necessitam de parâmetros metodológicos que a as norteiem".

Pode parecer estranha uma produção artística, que lida com a criação, a sensibilidade, "amarrada" em uma abordagem metodológica. Como essa pesquisa pode ser suscetível a um conjunto de regras estabelecidas e tirar algum proveito disso? Será que o resultado final não será algo igual ou parecido com o que já foi desenvolvido utilizando o mesmo caminho? Muitas podem ser as perguntas em relação à utilização de metodologias nas artes visuais, mas deve-se levar em consideração que a produção artística acadêmica possui suas peculiaridades, pois o artistapesquisador deve, segundo Peled (2012, p. 116), "articular suas poéticas pessoais dentro de uma estrutura acadêmica, e também pela complexidade que transpassa a produção de um volume de escrita acadêmico". Essa dupla produção deve complementar-se, uma dando suporte para a outra, em um processo integrado, sem buscar soluções conclusivas, mas instigando durante a ação a novos questionamentos e investigações que podem gerar ainda novas conexões pertinentes ao trabalho do artista. 
Essas conexões podem se "auto alimentar", criando novos questionamentos relacionados que possivelmente levam o pesquisador para caminhos que não haviam sido explorados anteriormente durante a pesquisa.

Sendo assim, busca-se nesse artigo explorar a metodologia cartográfica proposta por Deleuze e Guattari, que se apresenta bem aberta e sem amarras, com suporte e relacionamento com o campo das artes visuais através da exploração adicional feita principalmente por Virgínia Kastrup. A cartografia propõe essa criação de conexões e significação ao longo do desenvolvimento, mapeando pensamentos, técnicas, situações, pessoas, lugares, enfim, fazendo acoplamentos que constroem um panorama no campo do pensamento e no campo visual, produzindo práticas, técnicas e teorias que farão parte de seu trabalho.

\section{CARTOGRAFIA E MAPEAMENTO}

A cartografia, em sua origem de significado, relacionando-se com a geografia e os mapas, pode ser entendida como responsável pela representação visual do espaço geográfico. Possui como o suporte material da imagem do espaço que está sendo trabalhado o mapa. Geograficamente, é a representação do espaço, conceitualmente demarcada e condicionada historicamente.

Ao falarmos de mapa, a geografia é o que vem em mente. Culturalmente, é a associação direta mais comum, de acordo com Martinelli (2005, p. 1). E os mapas seriam a própria geografia, como sinônimos. Eles surgiram há muito tempo, sendo feitos em argila ou pedra, em peles de animais, em estruturas montadas para representação do espaço, ambiente e atividades. Não só apresentam visualmente o território físico, mas também relações sociais e comunitárias. Essas relações são apresentadas através de um "saber socialmente construído; portanto, uma forma manipulada do saber. São imagens carregadas de julgamentos de valor Não há nada de inerte e passivo em seus registros" (MARTINELLI, 2005 p. 2). Como podemos ver, mesmo no sentido mais comum de associação da cartografia, temos toda uma camada de relevância de pensamento, não ficando atrelada somente à representação gráfica.

Ao longo dos tempos, os mapas estão presentes desde a pré-História, em pinturas rupestres. Os primeiros desenhos não eram relacionados com território terrestre, mas com representações de formações celestes e constelações. Já na Babilônia, há registros de mapas feitos em barro representando porções geográficas do terreno, como rios e montanhas. O mapa mundi mais antigo que se tem registro possui origem babilônica também, de cerca de 600 a.C. Na Antiguidade clássica, com o pensamento grego, o interesse nos mapas foi responsável pela expansão de áreas de saberes. Assim como foram prosperando novas civilizações, novos meios de pensamento e campos de estudo, a cartografia acompanhou guiando esses processos e movimentos.

O avanço da cartografia aconteceu na Europa, relacionado ao Renascimento (séculos XIV e XVI), quando começaram as relações capitalistas, e a busca pela produção e negociação de mapas. Com a invenção da imprensa, a cartografia floresceu ainda mais, pois foi possibilitada a reprodução de mapas com um preço mais baixo, sendo assim mais fácil a sua propagação. $O$ acesso ao conhecimento geográfico e sociológico foi possibilitando o crescimento como um todo. Na era das grandes navegações, (séculos $X V$ e XVI), as nações possuíam muito interesse e necessidade de mapas cada vez mais corretos. As novas rotas marítimas permitiram uma troca cultural e acesso a diversas regiões desconhecidas, e a produção além de se especializar, aumentou significativamente (MARTINELLI, 2005, p. 2).

A partir do século XVIII, houve o surgimento da cartografia moderna, com a instituição de academias científicas. O conhecimento geográfico passou a ser estudado de maneira acadêmica. A partir do século XIX, com uma nova sequência de incursões imperialistas, os estados necessi- 
tavam mais uma vez de novos mapas, a fim de chegar a áreas passíveis de exploração e dominação.

Assim, ao longo da história, esses movimentos foram necessitando de maiores especializações e detalhes de representação, e foram surgindo campos específicos, tanto no campo da cartografia física, como nos aspectos sociais e culturais a serem representados, conhecidos como mapas temáticos. Para Clutton, “o mapa temático apresenta uma organização mental do espaço: ela generaliza e reordena as informações além de seus limites originais, para exprimir visualmente variedades mais abstratas" (MARTINELLI 2005, p. 4).

$$
\begin{aligned}
& \text { Brian Harley apontou para as diferentes formas de } \\
& \text { traduzir as imagens cartográficas como representações } \\
& \text { culturais carregadas de mensagens políticas, seja nos seus } \\
& \text { conteúdos explícitos, nas distorções e ausências, nos signos } \\
& \text { convencionais ou no claro simbolismo das decoraçôes de } \\
& \text { suas margens, cartuchos e vinhetas. Sublinhou também a } \\
& \text { necessidade de estudos mais aprofundados sobre cada } \\
& \text { contexto histórico específico, para compreender como o poder } \\
& \text { opera através do discurso cartográfico, e os efeitos desse } \\
& \text { poder na sociedade. (GOMES, 2004, p. 17) }
\end{aligned}
$$

Os mapeamentos de territórios foram progredindo juntamente com o avanço das sociedades, e a cartografia sempre esteve fortemente conectada com esse avanço. Nesse caso, não só a cartografia geográfica, com mapas e representações, mas também como interface de conexões, estudo de diversos fatores da sociedade e cultura.

O mapa, enfim, não pode ser considerado somente como um conjunto de representações gráficas, mas é um meio de comunicação, um artefato que apresenta e transmite informações com com- plexidade semiótica. Não apenas é um registro da paisagem, mas é como uma resposta do que é identificado, observado e selecionado de acordo com os interesses do projeto (MARTINELLI, 2005, p. 4) Ou seja, os fluxos de ideias e pensamentos também podem ser mapeados. A transmissão e recebimento de informações, as vivências e toda uma gama de subjetividades.

\section{CARTOGRAFIA COMO MÉTODO DE PESQUISA}

Não só de mapas e geografia é construída a cartografia. Apesar de ser sua origem, e mais comumente relacionada a esse aspecto, a cartografia também pode ser entendida como método de pesquisa, auxiliando o pesquisador a traçar seu caminho enquanto apreende e é apreendido pelas circunstâncias. Como em um mapa a ser desenhado, o pesquisador pode seguir um percurso sem um final claramente definido, e as ações e reações dessa paisagem se conectam e criam novos significados para a investigação.

Gilles Deleuze e Felix Guattari abordam a cartografia nesse contexto, como construtora de conexões, em torno de processos complexos e situações cotidianas. Diferentemente do desenvolvimento gráfico de mapas, relacionados principalmente a um território físico, os autores versam a respeito da cartografia como um meio para interligar aspectos da pesquisa, inclusive elementos que aparentemente não teriam ligação, mas que podem sim estabelecer conexões que propiciam resultados e questionamentos importantes. Assim, tenta-se diminuir as fronteiras entre o pesquisador e o campo de pesquisa, em busca dessas conexões. Deleuze e Guattari, referem-se à cartografia não no mesmo sentido da geografia, mas apoderam-se do termo dando significado ao planejamento de mapas em um território existencial e subjetivo. 
Um território desse tipo é coletivo, porque é relacional; é politico, porque envolve interaçôes entre forças; tem a ver com uma etica, porque parte de um conjunto de criterios referências para existir: e tem a ver com uma estética, porque é através dela como se dá forma a esse conjunto, constituindo um modo de expressão para as relações, uma maneira de dar forma ao próprio território existencial. Por isso, pode-se dizer que a cartografia é um estudo das relações de forças que compõem um campo específico de experiências. (FARINA, 2008 , p. 8)

Diferente de outras metodologias de pesquisa, a cartografia apresentada pelos autores não possui etapas formuladas ou procedimentos específicos a serem seguidos. Como uma parte do rizoma, não tendo entradas e saídas estabelecidas, a metodologia cartográfica não é como um procedimento tradicional. O rizoma constrói ligações sem início nem fim, sem um centro. Não há uma hierarquia, mas sim subdivisões que podem ser tão importantes quanto qualquer outra.

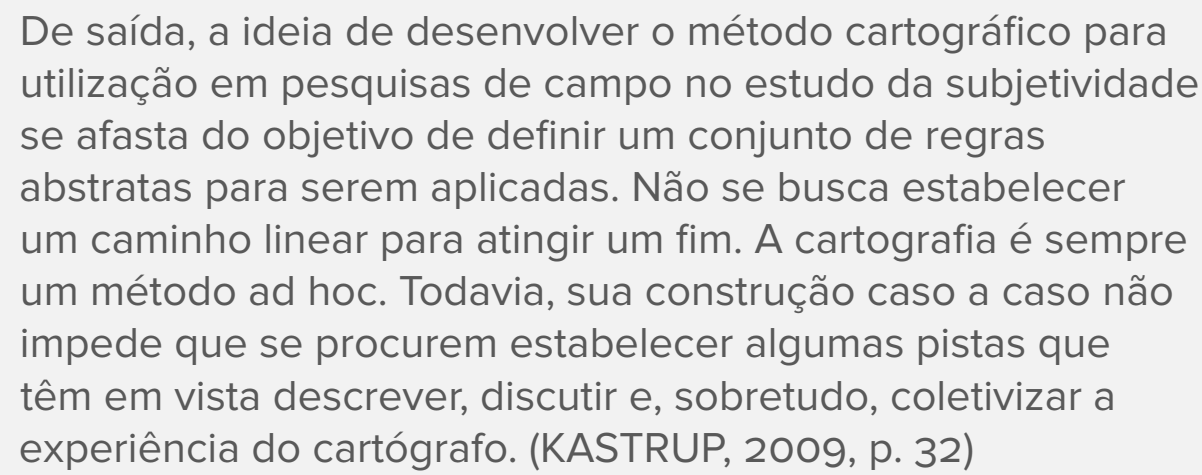

A cartografia possui uma direção inversa, segundo Kastrup (2014, p. 11) "essa reversão consiste numa aposta na experimentação do pensamento - um método não para ser aplicado, mas para ser experimentado e assumido como atitude". Ou seja, ao utilizar a metodologia cartográfica, o pesquisador é um cartógrafo, e assim deve participar ativamente do campo em que está inserida sua pesquisa, para assim conseguir mapear esses fluxos e estabelecer as conexões. O rigor metodológico é tomado aqui como o comprometimento, o interesse e intervenção. A cartografia é um acompanhamento de percursos e a percepção e desenvolvimento das conexões em rizomas, "inteiramente voltado para uma experimentação ancorada no real" (DELEUZE; GUATTARI, 1995, p. 21).

Como método de pesquisa, a cartografia não é um método que se aplica, conforme as palavras de Kastrup. Ele deve ser praticado, vivenciado pelo pesquisador. É um processo de criação que se reinventa enquanto se pesquisa, e ao passo que a investigação está em curso, juntamente com o objeto de estudo, de acordo com as necessidades que aparecem (FARINA, 2008, p. 9)

É necessário prestar atenção nos movimentos e situações que intervém na pesquisa, sabendo quais suas circunstâncias, efeitos e consequências. Como proposto por Deleuze e Guattari, a cartografia aproxima o pesquisador do subjetivo, pois "cartografar é acompanhar um processo, e não representar um objeto", segundo Kastrup (ALVAREZ; PASSOS, 2009, p. 45).

Assim, reforça-se a questão da diferenciação entre a cartografia geográfica e a cartografia como método de pesquisa. Elas, sim, são relacionadas, mas não são a mesma coisa. O objeto de pesquisa pode não ter relação com expressão gráfica de territórios físicos, mas estabelecer-se nas questões subjetivas de um ambiente de pensamento. Sueli Rolnik estabelece a diferenciação entre o mapa, que seria a "representação de um todo estático" e a cartografia, "um desenho que acompanha e se faz ao mesmo tempo que os movimentos de transformação da paisagem" (ROLNIK, 1989, p. 23). O mapa é a materialização, a representação de imagens, e a cartografia é responsável pela criação dessas imagens, ou seja, o processo. 
[...] cartografar o subjetivo tem a ver com atender às conexões que ele estabelece com o mundo no presente. Nessa perspectiva, uma pesquisa não desenha um mapa fixo ou histórico, mas estuda as relações, os encontros com o mundo, as forças em movimento desprendidas nesses encontros,

enquanto eles acontecem. (FARINA, 2008, p. 10)

Esse "mapa" que está sendo desenhado é aberto, beneficiando-se das entradas oferecidas pelo campo da pesquisa, das conexões criadas, dos movimentos e interações apresentadas e captadas pelo cartógrafo, incluindo suas próprias motivações e curiosidades. O pensamento múltiplo pode ser entendido como uma das bases da cartografia, como no rizoma.

$$
\begin{aligned}
& \text { [...] um mapa é um cenário de relevâncias que não são ditadas } \\
& \text { apenas pelo cartógrafo, mas também pelo cartografado e } \\
& \text { pelos que contribuem para a cartografia; é uma expressão de } \\
& \text { pontos de vista, um jogo entre presenças e ausências, não } \\
& \text { um retrato do que "está lá", mas um registro dos sentidos } \\
& \text { percebidos, dos significados que atribuímos ao que pensamos } \\
& \text { que lá esteja, um jogo de escalas [...] (GARNICA, 2013, p. 46) }
\end{aligned}
$$

O rizoma como apresentado por Deleuze e Guattari não se organiza como as raízes ou como os galhos de árvores, com separações bem definidas e encaminhadas separadamente. Ele é não-linear, multi-planar, capaz de conectar pontos de qualquer natureza com algum outro ponto.

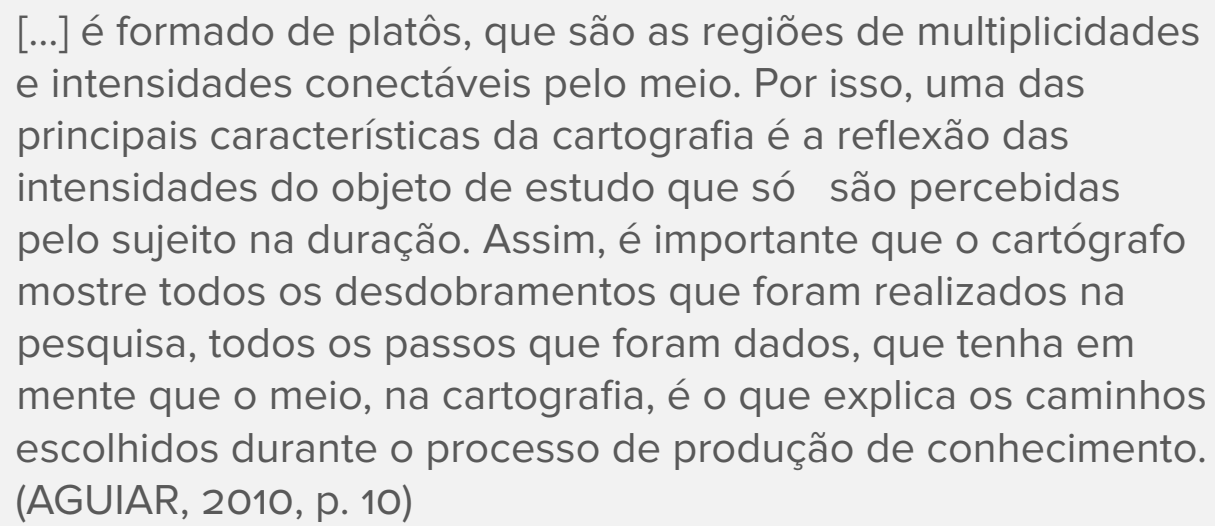

DARALELO31
A cartografia possui a peculiaridade de não possuir um plano a ser executado, uma lista de passos a ser seguido. Assim, ao investigar um objeto de estudo amplo, aberto, irrigado de subjetividade, o pesquisador pode seguir de maneira não-linear a sua verificação. $O$ processo vai se desdobrando e assumindo dimensões que levam a pesquisa para novos lugares.

No método cartográfico, a investigação da paisagem é algo constante. A paisagem que sempre se altera, a cada novo acoplamento, cada ligação que é feita entre ações, conceitos ou pensamentos. É como seguir caminhando sem saber o caminho, determiná-lo enquanto o percorre, em deriva. Assim como o objeto da pesquisa pode ser construído ao longo do trajeto, as estratégias de pesquisa também. O processo é onipresente na pesquisa, "nos avanços e nas paradas, em campo, em letras e linhas, na escrita, em nós, ou seja, a partir do reconhecimento de que o tempo todo estamos em processo, em obra" (AGUIAR, 2010, p. 2).

A prática, a vivência, é necessária, "ir a campo, seguir processos, lançar-se na água, experimentar dispositivos, habitar um território, afinar a atenção, deslocar pontos de vista e praticar a escrita" (PASSOS; KASTRUP; ESCÓSSIA, 2009, p. 203). Assim, o pesquisador poderá mapear esses fluxos e movimentos que serão o corpo de sua pesquisa, produzindo conhecimento. Envolvendo-se com a paisagem em mutação, os próprios objetivos da pesquisa podem mudar. Essa falta de rigidez não apenas faz parte da cartografia, como é o cerne que a define. Segundo Kastrup (2009, p. 204), "a cartografia como método de acompanhamento de processos de realização é ela mesma processual, lançada também em uma deriva feita de desvios e reconfigurações". Assim, o pesquisador está inserido de uma maneira diferente, não apenas coletando dados, mas sim processando dados, produzindo-os. De acordo com Rolnik (1989, p. 3), o cartógrafo: 
[...] absorve matérias de qualquer procedência. Não tem o menor racismo de frequência, linguagem ou estilo. Tudo o que der língua para os movimentos do desejo, tudo o que servir para cunhar materia de expressão e criar sentido, para ele é bem-vindo. Todas as entradas são boas, desde que as saídas sejam múltiplas. Por isso o cartografo serve-se de fontes as mais variadas, incluindo fontes não só escritas e nem só teóricas. [...] O cartografo e um verdadeiro antropófago: vive de expropriar, se apropriar, devorar e desovar, transvalorando. [...] a linguagem, para o cartografo, não e um veiculo de mensagem-e-salvação. Ela é, em si mesma, criação de mundos. [...] Restaria saber quais são os procedimentos do cartógrafo. Ora, estes tampouco importam, pois ele sabe que deve "inventá-los" em função daquilo que pede o contexto em que se encontra. Por isso ele não segue nenhuma espécie de protocolo normalizado. O que define, portanto, o perfil do cartógrafo é exclusivamente um tipo de sensibilidade, que ele se propõe a fazer prevalecer, na medida do possível, em seu trabalho. [...] É muito simples o que o cartógrafo leva no bolso: um critério, um princípio, uma regra e um breve roteiro de preocupações - este, cada cartógrafo vai definindo para si, constantemente $[\ldots]$.

Aproveitando, utilizando e participando dessa paisagem, a pesquisa cartográfica possibilita a construção ativa do conhecimento como processo criativo, abrindo espaço para a intervenção do pesquisador e do objeto de pesquisa. "É necessário refletir que ela não é um método pronto e fechado para se aplicar numa pesquisa, mas podemos pensar nela como uma deriva metodológica” (AGUIAR, 2010, p. 13).

Enfim, podemos perceber a grande abrangência do método cartográfico e sua liberdade projetual, diferentemente de outros métodos com passos determinados, aberta ao trabalho do investigador para vivenciar as conexões que o guiarão durante o estudo. A imersão do pesquisador em sua pesquisa é algo que possui grande importância aqui, e Virgínia Kastrup diz que não basta darmos o nome de cartografia ao método utilizado no trabalho, pois isso não é nenhuma garantia de qualidade e êxito. Para isso, devemos estar atentos "aos movimentos da subjetividade e da paisagem existencial, suas pontas de presente, seus fios soltos, suas linhas de fuga em relação à estratificação histórica” (PASSOS, KASTRUP, ESCÓSSIA, 2009, p. 203).

\section{REFERENCIAS BIBLIOGRÁFICAS}

AGUIAR, Lisiane Machado. As potencialidades do pensamento geográfico: a cartografia de Deleuze e Guattari como método de pesquisa processual. In: XXXIII Congresso Brasileiro de Ciências da Comunicação. 2010.

ALVAREZ, Johnny; PASSOS, Eduardo. Cartografar é habitar um território existencial. Pistas do método da cartografia: pesquisa-intervenção e produção de subjetividade. Porto Alegre: Sulina, 2009.

CATTANI, Icleia Borsa. Arte Contemporânea: e o lugar da pesquisa. In: BRITES, Blanca; TESSLER, Elida. O meio como ponto zero: Metodologia da pesquisa em artes plásticas. Porto Alegre: Ed. Universidade/UFRGS, 2002.

DELEUZE, Gilles: GUATTARI, Félix Introduç̃̃o: rizoma. Mil platôs, v. 1, p. 11-38, 1995

KASTRUP, Virgínia; ESCÓSSIA, Liliana da; PASSOS, Eduardo.

Pistas do método da cartografia: pesquisa-intervenção e

produção de subjetividade. Porto Alegre: Sulina, 2009.

FARINA, Cynthia. Arte e formação: uma cartografia da experiência estética atual. ANPEd, 2008.

GARNICA, Antonio Vicente Marafioti. Cartografias contemporâneas: mapa e mapeamento como metáforas para a pesquisa sobre a formação de professores de Matemática. Alexandria, p. 35-60, 2013.

GOMES, Maria do Carmo Andrade et al. Velhos mapas, novas leituras: revisitando a história da cartografia. 2004.

MARTINELLI, Marcello. Os mapas da geografla. In: XXI Congresso Brasileiro de Cartografia. 2005.

PELED, Yiftah. Metodologias em Poéticas Visuais. Porto Arte, v. 19, n. 33, 2012.

ROLNIK, S. Cartografia sentimental: transformações contemporâneas do desejo. São Paulo: Editora Estação Liberdade, 1989. 